\title{
EU Case Law
}

\section{Fabrizio Esposito* and Lucila de Almeida European Union Litigation}

\author{
https://doi.org/10.1515/ercl-2021-0005
}

Abstract: This article provides an overview of cases decided by the Court of Justice of the European Union concerning contract law. The present issue covers the period between the beginning of July 2020 and the end of December 2020.

\section{General Law of Contract and Obligations}

\section{Stringent Conditions to consent to the Storing of Identity Document: Judgment in Case C-61/19 Orange Romania}

Orange Romania, a telecommunication company, was fined for having failed to demonstrate that the service user had given valid consent to the storing of their identity documents, within the meaning of Articles 2(h) and 7(1) Directive 95/46 and Articles 4(11) and 6(1)(a) Regulation 2016/679 (GDPR). This case is of particular interest since the declaration of consent Orange Romania relies upon is part of the contractual clauses and the Court of Justice of the European Union (CJEU) develops the guidance offered in Planet49 (judgment of 1 October 2019, C-673/17, EU:C:2019:801) on the conditions for consent being validly given under the GDPR.

Preliminarily, it should be noted that the GDPR repealed and replaced the Directive with effect from 25 May 2018, but the administrative decision was adopted before that date. In this regard, the Court of Justice chooses to analyse the case also in light of the GDPR as 'it is not inconceivable that ... Regulation 2016/679 is applicable ratione temporis' since the administrative order had not been complied with by 25 May 2018.

The first step of the reasoning reaffirms that under both the Directive and the GDPR, consent must be active. As now expressly stated by recital 32 GDPR, this

\footnotetext{
*Corresponding author: Dr. Fabrizio Esposito, LL.M. (EUI), is Assistant Professor of Law at the NOVA School of Law in Lisbon and a Lecturer at the Wageningen University \& Research.

Dr. Lucila de Almeida, LL.M. (EUI), is Assistant Professor of Law at the Wageningen University \& Research, and Part-time Assistant Professor at European University Institute, Robert Schuman Center for Advanced Studies, Florence School of Regulation.
}

Ә Open Access. (2021 Fabrizio Esposito and Lucila de Almeida, published by De Gruyter. (co)BY This work is licensed under the Creative Commons Attribution 4.0 International License. 
requirement means that 'silence, pre-ticked boxes or inactivity' cannot constitute active consent. As explained already in Planet49, it is impossible to infer consent from inactivity and, moreover, the data subject may not have read the 'information accompanying the preselected checkbox, or even ... noticed that checkbox' (para 37).

Secondly, the Court of Justice follows its reasoning at paragraph 58 of Planet49 to hold that, to be specific, consent 'must relate specifically to the processing of the data in question and cannot be inferred from an indication of the data subject's wishes for other purposes' (para 38). Elaborating on the issue further, the CJEU connects the requirement of specificity to the requirement of transparency set by Article 7(2) GDPR, read in conjunction with recital 42 thereof.

The third step interprets the provisions of the Directive and of the GDPR related to the requirement that consent is 'informed'. Elaborating more in detail the matter in comparison to the decision in Planet49, the Court articulates a rich and robust notion of consent, with both procedural and substantive elements. Procedurally, 'the controller is to provide the data subject with information ... in an intelligible and easily accessible form, using clear and plain language' (para 40). Substantively, the information must be 'relating to all the circumstances surrounding the data processing, ... allowing the data subject to be aware of, inter alia, the type of data to be processed, the identity of the controller, the period and procedures for that processing and the purposes of the processing' (para 40). Overall, 'the data subject must be able to determine easily the consequences of any consent he or she might give and ensure that the consent given is well informed' (para 40).

In the fourth step of the analysis, the Court of Justice agrees with the Commission in finding that the Directive and the Regulation express the idea that the 'data subject enjoys genuine freedom of choice' and can be considered to express an informed consent only when he or she is not misled about 'the possibility of concluding the contract even if he or she refuses to consent to the processing' (para 41).

Finally, the CJEU reminds that the burden of proving the validity of consent lies with the data controller. While this requirement is explicitly stated by Article 7(1) GDPR, it is noteworthy that the Court follows the Advocate General in inferring the same requirement in interpreting the Directive. More precisely, the data controller bears the burden of proof under the Directive because the consent of the data subject must be unambiguously given pursuant to Article 7(a) of the Directive.

Based on these findings about the conditions allowing a data controller to rely on consent to process personal data, the Court of Justice examines the position of Orange Romania. The CJEU focuses first of the service provider's submission that the checkbox was ticked by the sale agents. This practice 'does not, on 
its own, prove ... consent, in the absence of any indications confirming that that clause was actually read and digested' (para 46). In other words, the sale agents, by ticking the box in the place of the data subject, have turned the data subject's duty to read the clause into the controller's duty to prove that that clause was actually read and digested. The last word rests with the referring judge.

The Court of Justice then expresses doubt, leaving the last word to the referring judge, about whether consent was specific, informed and freely given. The CJEU is doubtful about consent being specific as the clause 'does not appear to have been presented in a form which clearly distinguishes it' (para 47).

With regard to consent being informed, the Court identifies two issues. First, the clause might be too vague as it 'merely states, without giving any further details, that storage of the copies of the identity cards is for identification purposes' (para 48). Second, the consent might be uninformed as the data subject might have been misled 'as to the possibility of concluding the contract notwithstanding a refusal to consent to the processing of his or her data' (para 49).

Finally, the Court of Justice criticises the request that the data subject 'declares in writing that he or she did not consent to a copy of his or her identity document being collected)' (para 50). First, the CJEU agrees with the Advocate General and the Commission in 'call(ing) into question the free nature of consent' under these circumstances, as 'such an additional requirement is liable to affect unduly the freedom to choose to object to that collection' (para 50). Second, to nail the coffin on the data controller and without much elaboration, the Court infers for the duty to prove that consent was given from active behaviour that 'that company cannot require [data subjects] actively to express their refusal' (para 51).

With the present decision, the Court of Justice articulates a very demanding notion on valid consent under both the Directive and the GDPR. When asked to prove that consent was specific, the data controller will have to show that the clause was 'read and digested' (para 46). The notion of informed consent is particularly thick both in abstract terms (para 40) and as specifically applied to the facts (paras 48 and 49). Moreover, asking to sign a form to confirm that one denies consent might be enough for such consent not being freely given (50). Under these circumstances, one may wonder how often data controllers can succeed in obtaining a valid declaration of consent. 


\section{A Public Work Contract Constitutes a Commercial Transaction for the Late Payment Directive: Judgment in Case C-299/19 Techbau}

Could national law exclude public work contracts from the concept of commercial transaction within the meaning of Article 2(1) of Directive 2000/35 combating late payment (Late Payment Directive)? This case is of particular interest since the Court not only revisits the concept of commercial transactions; the Court also interprets the meaning of 'transactions which lead to the delivery of goods or the provision of services' in order to clarify whether it applies to a 'public work contract' under Italian law.

In essence, the decision referred to a dispute between Techbau SpA and an Italian authority concerning a public work contract, which consists in a turnkey delivery and fitting-out of an operating block for a hospital. Techbau SpA brought an action seeking for default interest for delay in the payment. To resist the claim, the Italian authority argued that the contract at issue was a 'work contract for the realisation of work' (para 28) and, therefore, excluded from the category of contracts for the delivery of goods or the provision of services in accordance with the Italian legislative decree that transposed the Directive.

Preliminarily, it should be noted that the Italian Republic had exercised power to exclude contracts before 16 March 2013 when transposing Directive 2011/7, which recasts the Late Payment Directive of 2000. However, the latter is still applicable ratione temporis to the contract at issue, as it was concluded in April of 2010.

Regarding the concept of commercial transactions, the Court of Justice acknowledges that the first subparagraph of Article 2(1) does not expressly mention public work contracts in the definition of commercial transactions. Still, that provision also expresses no reference to the law of Member States to determine its meaning. Therefore, the provisions of Article 2(1) 'must be given an independent and uniform interpretation throughout the European Union' (para 38).

Said that, the reasoning of the Court of Justice deploys four legal arguments to leave no doubt that a public work contract constitutes a commercial transaction within the meaning of Article 2(1) of the Late Payment Directive. In the first place, the CJEU recalls its recent decision in $R L$ (judgment of 9 July 2020, C-199/ 19, EU:C:2020:548), which sets a textual interpretation of Article 2(1). Accordingly, a commercial transaction has two elements. Firstly, it must be 'carried out between undertakings or between undertakings and public authorities'. Secondly, it 'leads to the delivery of goods or the provision of services for remuneration' (para 39). While the first conditions raised no doubts for the referring court, the second condition deserves attention. Article 1 of the Directive, in light of the recitals 13 and 22, must apply to all payments between undertakings and public 
authorities, excluding only transactions with consumers and the payments listed under Article 6(3) (para 41). That list does not include public work contracts and, therefore, there is no reason to exclude that type of contract from the scope of the Directive.

In the second place, the Court of Justice refers to the meaning of goods and services in the Treaty. There can be no doubt that a work contract involves the delivery of a good or the provision of a service within the meaning of Articles 28 and 57 TFEU (para 52). By analogy, it is hard to conclude differently when establishing the meaning of goods and services in the Directive.

In the third place, the Court refers to the teleological interpretation in $K R O L$ (judgment on 28 November 2019, C-722/18, EU:C:2019:1028). The objective of the Late Payment Directive is to harmonise the consequences of late payment. Therefore, the exclusion of a not-insignificant portion of the commercial transactions between undertakings and public authorities would run counter the objective of the Directive and its effectiveness (para 54).

In the fourth and last place, the Court also refers to the explanatory memorandum of the Directive's proposal. In 1998, the Commission justified the necessity of the Directive as a means to reduce the contractual unbalance between undertakings and public authorities because of late payments, citing exactly the construction sector as one example (para 56).

Regarding all of the foregoing, the judgment leaves no doubt that the Italian law, which distinguishes a work contract for the realisation of work from a contract for the delivery of good and services, is incompatible with the Directive.

\section{Consumer Protection}

\section{General Consumer Protection}

\section{Full-Time Poker Player as a Consumer: Judgment in Case C-774/19 Personal Exchange International}

Does the concept of a consumer within the meaning of Regulation (EC) 44/2001 cover a person who plays online poker 9 hours per day, makes a living out of this activity and is an expert in the game? This question may sound rhetorical, as one would expect that such a person has turned online poker playing into his profession. However, this is not the straightforward view of the Court of Justice in the present judgment, still unavailable in English.

The reasoning of the CJEU starts with the observation that Article 15(1) of the Regulation shall be interpreted narrowly, as it is an exception. Citing Schrems 
(judgment of 25 January 2018, C-498/16, EU:C:2018:37, para 30), the Court points out that only contracts concluded outside and independently of any trade or professional activity, solely for the purpose of satisfying an individual's own needs in terms of private consumption, are covered by the special rules laid down by the Regulation to protect the consumer as the party deemed to be the weaker party.

Moving from these premises, one would expect the 9-hour-per-day poker player making a living out of the game not to be considered a consumer for the purposes of the application of Article 15(1) of the Regulation. However, the CJEU takes a more complex and ultimately opaque argumentative route. First, the amount of the gain is not, 'in and of itself', an element that is relevant for the interpretation of the provision (para 34). This finding is warranted by the need to ensure the certainty for the poker player of the regime applicable. However, in Kamenova (judgment of 4 October 2018, C-105/17, EU:C:2018:808, para 39), in relation to the notion of a trader in the application of the Unfair Commercial Practices Directive, the CJEU had held that whether an activity is 'intended to generate profit' is relevant to decide whether a natural person is a trader or not.

Second, the expertise of the player is also irrelevant since the notion of a consumer is objective. While this observation is in line with the case-law, it should be noted that in Kamenova the CJEU held that to decide whether a natural person is a consumer or a trader one has to consider, inter alia, "whether the seller had technical information and expertise relating to the products which she offered, with the result that she was placed in a more advantageous position than the consumer' (C-105/17, para 38).

It is only in the third step of the analysis that the CJEU hints to the possibility of not considering the poker player in the main proceedings as a consumer. The Court leaves to the referring judge the task of establishing if the contract, originally concluded for consumption purposes, later acquired a professional character. Unfortunately, the CJEU does not elaborate on the matter further, although it seems reasonable to conclude that, on these grounds, the poker player shall not be considered a consumer within the meaning of Article 15(1) of the Regulation.

Next, the Court of Justice articulates systematic considerations, related to the notion of a consumer as developed in the interpretation of Directive 2005/29/EC and Directive 2011/83/EU. In particular, the CJEU finally quotes its decision in Kamenova to hold that an activity's regularity is relevant to decide whether the poker player is a consumer or a professional. In so doing, the Court distinguishes between situations where the natural person sells goods or provides services, and those where, like in the main proceedings, the natural person does not. Notably, the CJEU does not explain the relevance of the distinction for providing the guidance asked by the referring judge. 
The present decision clearly illustrates the difficulty of establishing the subjective scope of application of EU consumer law. In our opinion, the decision also shows that the Court of Justice's argumentative scheme in this area, so reliant on the idea that the notions of a consumer, trader, professional, etc, are functional and objective, might require judicial or legislative development. This is especially the case since giving space to the subjective purpose of the contract for the natural person suggests that the CJEU is willing to go beyond an objective interpretation. ${ }^{1}$

\section{Information Duties}

\section{Information in the Packaging of Imported Cosmetic Products and the Mem- ber State's Language: Judgment in Case C-667/19 E M (Étiquetage des pro- duits cosmétiques)}

The owner of a beauty salon in Poland bought cosmetic products from an American producer but decided to resolve the contract by the default of the product. The buyer claimed the information on the product's function did not appear on the packaging in Polish. On the other hand, the seller ensured that the product had been labelled in accordance with Regulation 1223/2009 concerning cosmetic products. In particular, the seller submitted that a symbol representing a hand with an open book appearing on the product constituted a reference to a separate company catalogue according to point 1 of Annex VII of the Regulation.

Since the action seeking reimbursement of the costs of purchasing those products was dismissed, the buyer brought an appeal. The Commercial section of Appeal of Warsaw Regional Court referred to the Court of Justice the following question: Is the symbol with an open book on the product sufficient to inform an average consumer about the product's function in question? The question may sound an easy one, but it gave the Court the chance to rule on the use of a separate company catalogue as means to comply with the European rules on the information in packaging. The judgment is still unavailable in English.

The reasoning of the Court of Justice starts with the interpretation of Article 19 (1) of the Regulation, which establishes that cosmetic products might only be made available on the market if the container and packaging bear the information about the function of the cosmetic product in indelibly, easily legible and visible

1 For a similar point in relation to Kamenova, see F. Esposito and P. Hacker, 'European Union Litigation' (2019) 15(1) European Review of Contract Law 66, 71-72. 
lettering. In other to interpret the meaning of the expression 'function of the cosmetic product', the Court refers to Article 2(1)(a) of the Regulation, which sets out three criteria for defining that product: nature of the product concerned, the parts of the human body which that product is intended to be placed on, and the objective pursued by the use of the product. Since Article 19(1) pursues the objective of harmonisation information duties for the protection of consumers' health, the obligation of informing on the function of the cosmetic product cannot be limited to merely indicating the objectives pursued by the use of the product. Containers and packaging of such products must inform the consumer about the use and how to use them to ensure that it can be manipulated safely by consumers.

Next, the Court of Justice considers whether the information concerning special precautions for the use of a cosmetic product and its ingredients may appear in a company catalogue, which also includes other products and where the symbol of a hand with an open book is placed on the cosmetic product's packaging or container. Article 19(2) provides that the information regarding the special precautions for use and the ingredients appear 'in an information leaflet, on the label, on a strap, on a badge or on a card included or accompanying the product' whenever, for practical reasons, it is not possible to include them in the labelling. The reasoning of the CJEU on this point can be divided into four steps.

First, there is a difference between Article 19(1) and (2). While the former concerns the information regarding the function of a product, the latter is about the precautions of use and the ingredients. The missing information in the packaging of the cosmetic product in the main proceeding seems to be related to the function of the product instead.

Second, the derogation provided for Article 19(2) of the Regulation must be interpreted in light of recital 46, which states that 'in the case of a practical impossibility of including the name of these ingredients on the packaging, these indications must be included in order to give the consumer access to that information' (para 41). When such reference is made, an information leaflet, a label, a strep a badge or a card must be included in or accompanying the product, instead of a separate catalogue.

Third, the CJEU considers the fact that the cosmetic products in question are imported, which gives rise to difficulties associated to the need to translate certain information and carry out new labelling operations or even new packaging. The Court takes the view that also these difficulties do not represent an impossibility of practical order within the meaning of Article 19(2) of the Regulation. Finally, 'the fact that labelling of a cosmetic product is the responsibility of someone who is a third party in the purchase and sale contract', namely the producer rather than the distributor, 'does not characterise a practical impossibility either' 
(para 48). The Court then reinforces that the costs of re-labelling imported cosmetic products in the Member State's official language is necessary to ensure consumer protection.

The judgment of the CJEU illustrates what is known as the theory of Brussels effect. $^{2}$ It depicts how the EU extends its influence beyond its borders when it imposes on foreign producers the obligation of complying with various internal market rules, among other things, on matters of consumer healthy and safety.

\section{Unfair Contract Terms}

\section{Negotiation to Avoid the Annulment of the Contract: Judgment in Case C-269/19 Banca B}

The Court of Appeal, Cluj, Romania, gave to the Court of Justice the opportunity to return on the issue of the power of national judges when a term is found unfair, the contract cannot continue into existence without the term, and annulling the contract would have particularly unfavourable consequences for the consumer. In Kásler and Káslerné Rábai (judgments of 30 April 2014, C-26/13, EU: C:2014:282), the Court found that in such circumstances, national courts may substitute the unfair term with a supplementary provision of national law. In Dziubak (judgment of 3 October 2019, C-260/18, ECLI:EU:C:2019:819), the Court of Justice restricted this power holding that general provisions cannot be used to this end.

The contract at issue in the main proceedings is a loan agreement, and the terms found unfair fall precisely into the Kásler exception. In particular, the interest rate consists of a fixed rate for the first year, and a variable rate determined by the bank plus a fixed margin of 1,5\%. The referring judge points out that the Romanian case-law is fragmented on the issue of the possible remedies for such terms. More precisely, the following four solutions have been applied: negotiation between the parties; an interest rate based on a fixed margin plus a benchmark, such as the Euribor; an interest rate equal to the fixed margin only; continuous application of the fixed rate originally intended to apply to the first year only. Against this background, the referring judge asked guidance on the compatibility of these solutions with EU law and, in particular, with the Unfair Contract Terms Directive.

2 A. Bradford, The Brussels Effect: How the European Union rules the World (Oxford: Oxford University Press, 2020). 
In essence, the CJEU found that only the negotiations between the parties is a compatible remedy with EU law 'provided that [the national court] sets out the framework for those negotiations and that those negotiations seek to establish an effective balance between the rights and obligations of the parties' (para 42).

The reasoning of the Court of Justice begins with familiar references to the asymmetrical nature of consumer contracts. Moving more specifically to the issue of the interpretation of Article 6(1) UCTD, the CJEU reminds that revising the content of unfair terms can compromise the dissuasive effective of the prohibition of the use of unfair terms set by Article 7 UCTD. Accordingly, national courts cannot substitute the unfair term, unless annulling the contract in its entirety would 'expose the consumer to particularly unfavourable consequences' (para 32). The exception is based on the observation that the annulment would 'penalise the consumer rather than the lender' (para 34).

However, in Dziubak the CJEU held that gaps could not be 'filled solely on the basis of national provisions of a general nature' because they 'are not covered by the presumption that they are not unfair' (para 35). In the present decision, the CJEU adds that 'the national court must, while taking into account all of its national law, take all the measures necessary to protect the consumer from the particularly unfavourable consequences' (para 41).

Based on these premises, the CJEU finds that negotiation between the parties is the only viable solution to avoid the already-mentioned particularly unfavourable consequences. The national court has, however, to exercise oversight over the process, by 'set(ting) out the framework for those negotiations' (para 43). In this regard, the CJEU warns national judges that they cannot go 'beyond what is strictly necessary to restore the contractual balance', explaining that doing otherwise would comprise the goals of ensuring the equality between the parties and putting and end to the use of unfair terms in consumer contracts (para 44).

The present decision is particularly interesting because it tries to bring the ruling in Dziubak in line with the consumer law acquis. One of us has pointed out that Dziubak raises significant concerns with regards to both the level of consumer protection and the division of powers between the Union and the Member States. ${ }^{3}$ With this decision, the CJEU takes explicitly into consideration the duty of national judges to 'take all the measures necessary to protect the consumer', but decides to narrow the scope of this duty to reconcile it with Dziubak. To justify this choice, the CJEU states that '(i)f the court were permitted to change or restrict

3 F. Esposito, 'Dziubak Is a Fundamentally Wrong Decision: Superficial Reasoning, Disrespectful of National Courts, Lowers the Level of Consumer Protection' (2020) 16(4) European Review of Contract Law 538. 
freely the content of the unfair terms, that power could undermine the achievement of' the objectives of the UCTD (para 44). This observation is puzzling, above all since it equates judges 'taking into account all of its national law' (para 41) to judges deciding 'freely' (para 44).

Be this as it may, the solution of a 'supervised negotiation' is an interesting one. Indeed, the UCTD moves from the premise that terms that have been individually negotiated fall outside the scope of the Directive. However, in a normal situation, consumers would rely on the ability to shop around in the negotiations. As this ability is drastically limited in a situation such as the one in the main proceedings, the CJEU has decided that the national judge shall exercise oversight. The decision raises interesting empirical questions about the extent to which this oversight can substitute the market in disciplining traders in individual negotiations. Moreover, one can foresee that this judicial oversight will be challenging to exercise. National courts will have to avoid leaving too much manoeuvre to the lender and entering too much into the merits. The first alternative would compromise the effectiveness of the UCTD, while the second would violate the constraints introduced by Dziubak.

For these reasons, it is unclear whether the CJEU has succeeded in reconciling Dziubak with the consumer law acquis.

\section{Passenger Rights}

\section{Offering Hotel Accommodation in Case of Flight Cancellation Does not Mean Taking Care of the Accommodation Arrangements: Judgment in Case C-530/ 19 Niki Luftfahrt}

ON's flight operated by Niki Luftfahrt was cancelled and, in compliance with Articles 5(1) and 9(1)(b) of Regulation 261/2004, the air carrier offered a hotel accommodation to ON. Unfortunately, during the stay in the hotel, ON was seriously injured in consequence of falling from her wheelchair because of an obstacle in the pathway.

With its preliminary reference, the Austrian Supreme Court seeks guidance on the limits of the obligation to offer an accommodation and, in particular, whether this obligation leads to liability for the negligent conduct of the hotel employees. More precisely, the first question ventilates the hypothesis that poor performance of the obligation to offer accommodation can be equated to its non-performance, noting however that the compensation scheme under the Regulation is not welldesigned for this hypothesis. The second question, more fundamentally, asks whether, under the Regulation, the air carrier is liable for the selection of the hotel 
only, or for the conduct of the employees of that hotel as well. In support of the broader interpretation, the Austrian Supreme Court invokes the need to ensure a high level of passenger protection. Next, it observes that the air carrier could seek redress against the hotel. Considering the fact that 'the obligation to accommodate a passenger in a hotel must be performed only in the event of a shortcoming on the part of the air carrier', the Austrian Supreme Court submits that 'it would be logical for the air carrier and not the passenger to bear the risk of legal proceedings brought before a court of a Member State other than that in which that carrier has its seat' (para 19).

The Court of Justice opts for a different approach. From a logical point of view, the CJEU prefers answering the second question first. The first step of the analysis finds that from the wording of Article 9(1)(b) it is possible to infer that the article is intended to 'prevent passengers ... from having to bear the burden of finding a hotel room and of paying the costs thereof' (para 24). The wording is inconclusive about the provision of the accommodation service.

To answer this question, the CJEU considers the parallel obligation established by Article 9(2), requiring the air carrier to offer two telephone calls or emails. The Court reasons that this obligation does not require the air carrier 'to organise, on its own responsibility, the implementation of the telecommunications operations necessary for that purpose' (para 25). Likewise, the air carrier cannot be considered responsible for the provision of the accommodation service.

The Court of Justice finds that such an interpretation is confirmed, contrary to the submission of the Austrian Supreme Court, by the protective objectives of the Regulation, which the CJEU understands as ensuring that the passengers 'are adequately cared for while awaiting a later flight' (para 26). Importantly, the CJEU notes that Article 5(1) applies independently of the cause of the cancellation of the flight. In so doing, an important premise of the reasoning of the Austrian Supreme Court is rejected, namely that the cancellation was triggered by some 'shortcoming' of the air carrier.

In essence, the CJEU qualifies the relationship created pursuant to Article 9 (1)(b) in the sense that the air carrier acts as an agent with representation of the passenger, who enters into a contract with the hotel. Consistently with this view, the Court of Justice does not release the air carrier from all responsibility: 'the air carrier must select the hotel carefully, having ascertained that the hotel is capable of meeting reasonable expectations in terms of quality and safety' (para 29).

Moving from these premises, it is unsurprising that also the answer to the first question is in favour of the air carrier. On the one hand, the answer to the second question has clarified the stringent requirements for finding the air carrier responsible for the poor provision of the accommodation service by the hotel. On the 
other hand, the Court of Justice cites its decision in Rusu (judgment of 29 July 2019, C-354/18, EU:C:2019:637, para 31) to hold that the Regulation 'does not provide for the compensation of individual damage, redress for which requires a case-by-case assessment' (para 38).

In the unlikely event that the passenger establishes the liability of the air carrier for negligent selection of the hotel, the answer to the second question may raise doubts about whether the Regulation could be invoked to claim compensation under national law. A close examination of the right to further compensation granted by Article 12 of the Regulation would be needed to answer this question. It is nevertheless apparent that limiting the liability of the air carrier for its failure to carefully select the hotel would limit the effectiveness of the obligation under Article 9(1)(b) Regulation.

\section{Service Law}

\section{E-Commerce of Medical Products not Subject to Medical Prescription be- tween National and EU Law: Judgment in Case C-649/18 A (Advertising and Sale of Medicinal Products online)}

The present case concerns the compatibility with EU law and, in particular, with Directive 2000/31 (E-Commerce Directive) of national legislation that introduces the following restrictions to the online sale of medical products not subject to medical restriction: prohibition of certain selling procedures and methods, in particular the extensive sending of post and leaflets for advertising purposes; prohibition of promotional discounts once a certain amount is exceeded; requirement to include a health questionnaire; prohibition of using paid referencing on search engines and price comparison websites.

In essence, the Court of Justice is asked to examine the compatibility of these measures with Article 3 E-Commerce Directive. This task can be broken down in the following steps: does the measure fall within the concept of coordinated field (Article 2(h) E-Commerce Directive)? If so, does the measure restrict the freedom to provide information society services? If so, does the measure protect a public interest, including, among others, public health being prejudiced or put at serious and grave risk by the information society service? If so, is the measure adequate? If so, does the measure go beyond what is necessary? Finally, did the Member State follow the request and notification procedure set by Article 3(b) E-Commerce Directive?

Before examining these questions in relation to each of the measures, the Court of Justice notes that Directive 2001/85 is not relevant in the present case as 
it does not prohibit the sale at distance of medical products not subject to medical prescription. The CJEU also observes that it is inappropriate to assess the measures under Article 34 TFEU, which enshrines the free movement of goods, as doing so would 'undermin(e) the harmonisation in this area intended by that directive' (para 34).

With regard to the solicitation through the extensive sending of post and leaflets for advertising purposes, the Court of Justice has to decide if the notion of coordinate field covers online advertising only or also advertising carried out through physical media. Notably, the former, but not the latter, is mentioned explicitly by recital 21 E-Commerce Directive. The CJEU does not find this circumstance conclusive since advertising is meant to attract clients to the seller's website 'irrespective of the process by which it is actually carried out' (para 55). The prohibited advertising is, therefore, 'ancillary to and inseparable from' the online sale (para 56).

Moving from these grounds, the Court of Justice finds with no hesitation that the measure restricts the freedom of the service provider by limiting its ability to reach customers. In the next steps, the CJEU recalls its decision in Vanderborght (judgment of 4 May 2017, C-339/15, EU:C:2017:335) to hold that 'the protection of the dignity of a regulated profession' relates to the protection of public health (para 66). Then, it holds that the prohibition of large-scale advertisement is appropriate as the practice 'conveys a commercial and mercenary image [sic] of the profession of pharmacist' (para 70).

In analysing whether the measure goes beyond what is necessary, the Court reminds that the Member States are granted a margin of discretion, but that a 'general and absolute prohibition of any advertising ... goes beyond what is necessary'. The CJEU leaves the final word on the matter to the referring judge.

In relation to the second measure, the prohibition of promotional discounts once a certain amount is exceeded, the Court of Justice finds that the prohibition restricts the freedom of the service provider and is adequate to protect public health, in particular against the risk of over-consuming medical products. However, the CJEU leaves again to the referring judge the task of establishing if the measure goes beyond what is necessary taking in particular into consideration the pharmacist's observation that the measure prohibits any discount and also covers para-pharmaceutical products.

The third measure, the requirement of including a health questionnaire, limits the contractual freedom of the parties as the validation of the first order on the website depends upon completing the questionnaire. The Court of Justice finds quickly that the measure falls within the coordinate field and that it restricts the provider's freedom. Next, the CJEU finds that the measure protects public health 
as it is meant to ensure that consumers receive individual advice and are, therefore, protected from the misuse of medical products.

The analysis of whether the requirement goes beyond what is necessary ultimately relies on the discretion Member States enjoy. Notably, the pharmacist submitted that, in line with the Decree on best practices, it offers the 'possibility of a remote interactive exchange with a pharmacist' and it checks the orders in light of several parameters (para 98). After finding that the Member States have enough discretion to introduce a measure such as the one under consideration, ostensibly ad abundantiam, the CJEU agrees with the Advocate General that the practices submitted by the pharmacist are 'not as effective as verification carried out by means of the prior collection of information from the patient' (para 101).

In relation to the fourth measure, the prohibition of using paid referencing on search engines and price comparison websites, the national government submitted during the hearing that such prohibition is meant to ensure an appropriate distribution of pharmacies over the national territory. The Court of Justice found that this measure might be, in principle, adequate and proportionate. However, the national government defending the measure has failed to meet the burden of proof on the matter, to the effect that the final decision will have to be taken by the referring judge.

This decision touches on a number of complex issues, made particularly topical by the current pandemic. Regrettably, the Court of Justice has systematically avoided providing guidance on the application of the request and notification requirements set by Article 3(b) E-Commerce Directive. As at least part of the measures are likely to comply with Article 3(a) E-Commerce Directive, Article 3(b) will become relevant. In this regard, the Court could have shed light on the delicate issue of the interpretation of the said provision when a measure predates the ECommerce Directive and its application to an information society service provider is established in a judicial proceeding for the first time. ${ }^{4}$

4 A similar issue was present in Airbnb Ireland (judgment of 19 December 2019, C-390/18, ECLI:EU: C:2019:1112). For a comment, see F. Esposito and P. Hacker, ‘European Union Litigation' European Review of Contract Law 2020 16(1) 212, 217-218. 


\section{Discrimination Law}

Interpretation of the Equal Treatment Measures of Men and Women in Matters of Additional Maternity Leave in a Collective Labour Agreement: Judgment in Case C-463/19 Syndicat CFTC

The present case is about whether equal treatment demands that a father can enjoy an additional leave, which follows the statutory maternity leave, granted to female workers who bring up their child on their own. CY, a father in an analogous condition of a mother who brings up a child independently, had his request to additional leave denied by CPAM, his employer. The case is remarkable as the judgment establishes in what condition a national collective agreement can reserve to mothers alone an additional maternity leave without violating Articles 14 and 28 of the Directive 2006/54 on the implementation of the principle of equal opportunities and equal treatment of men and women in matters of employment and occupation.

Primarily, CPAM submitted that the CJEU has no jurisdiction in light of Article 267 TFEU, considering 'the Court is not being asked to rule on the interpretation of any EU law or on the validity of the interpretation of any act adopted by an institution, body or agency of the European Union' (para 27), but asked to interpret the provision of a collective agreement. Although the Court acknowledges that a combined reading of the referred question requests the ruling of the compatibility of a provision of national rules, the CJEU recalls CTT-Correiors de Portugal (judgment of 30 April 2020, C-661/18, EU:C:2020:335) to argue that there is nothing that prevents the Court to 'provide guidance as to the interpretation of EU law to enable that [national] court to determine whether these national rules are compatible with EU law' (para 29). Moreover, it is worth noticing that the Court had previously critically scrutinised collective agreements in the area of equal pay and equal treatment, such as in Bilka v Weber von Hartz (judgment of 13 May 1986, C-170/84, ECLI:EU:C:1986:204) and Kowalska v Freie und Hansestadt Hamburg (judgment of 27 June 1990, C-33/89, ECLI:EU:C:1990:265). ${ }^{5}$

Moreover, the French government submitted that the referred question did not satisfy the requirements laid down in Article 94 of the Rules of Procedures of the Court of Justice by not explaining the connection between that and a number of provisions of the TFEU and the Charter. The Court agreed that the reference is

5 See, generally, C. Welz, 'Transposition of EU Labour Law Directives Through Collective Agreements at National Level Collective Agreements: A Clash of Cultures' (2020) Eurofound Working Paper 2020, 32. 
succinct, but found it sufficient to understand the referring court's doubts. Moreover, the referring court does not request an autonomous interpretation of the TFEU and of the Charter, which justifies the focus of the ruling on Articles 14 and 28 of the Directive.

In the substance, the Court reinforces a clear distinction between the purposes of a right to maternity leave and an additional leave to the mother in her capacity as a parent. Following Hofmann (judgment of 12 July 1984, C-184/83, EU: C:1984:273) and Dicu (judgment of 4 October 2018, C-12/17, EU:C:2018:799), the maternity leave is intended, first, to protect a woman's biological condition during and after pregnancy and, second, the special relationship between a woman and her child over the period which follows pregnancy and childbirth (para 53).

In contrast to the statutory maternity leave, an additional leave may be granted through collective labour agreement as in the case at issue. On the one hand, the CJEU admits that a 'collective agreement which excludes from the benefit of such additional leave a male worker who is bringing up a child on his own establishes a difference in treatment between male and female workers' (para 60). On the other hand, however, the CJE states that 'only if such a difference in treatment seeks the protection of the mother in connection with the effects of pregnancy and motherhood, ... that [difference] appears to be compatible with Directive 2006/54' (para 61).

Although the Court of Justice concludes that is for the referring court to determine whether Article 46 of the collective agreement is compatible with EU law, the CJEU rules on the relevant factors that must be taken into account by the national court, namely 'the conditions for entitlement to the leave, its length and modalities of enjoyment, and the legal protection that attaches to that period of leave' (para 74).

First, the entitlement conditions to the leave must be indeed intended to protect female workers in connection with the effects of pregnancy and motherhood. Therefore, 'the mere fact that leave immediately follows the statutory maternity leave is not sufficient for it to be considered that it may be reserved for female workers who bring up their child on their own' (para 69). Second, the length and modalities of the leave may also be taking into consideration as relevant factors. An additional leave that 'is taken for one or two years, and is "unpaid", does not appear to ensure the maintenance of pay and/or entitlement to an adequate allowance for the female worker' (para 73), which is a condition for maternity leave according to Article 11(2) of Directive 92/85 on the introduction of measures to encourage improvements in the safety and health at work of pregnant workers and workers who have recently given birth or are breastfeeding. 


\section{Public Procurement Law}

\section{Pecuniary Interest in a Tender Submitted as a Price of Zero EUR: Judgment in Case C-367/19 Tax-Fin-Lex}

On 7 June 2018, the Ministry of the Interior of Slovenia published a contract notice for the award of a public contract concerning access to a legal information system. Although the estimated value of the contract amounted to 39.591,01EUR, Tax-FinLex proposed a price of 0,00EUR, but had its tender rejected by the Ministry. The latter based its decision on the single ground that the bid violated the rules on public procurement. With its request for a preliminary reference the national court asks whether a proposal of 0,00EUR is not a contract of pecuniary interest and, therefore, does not fulfil the meaning of a public contract in Article 2(1)(5) of Directive 2014/24 on public procurement.

Preliminarily, it should be noted that the tender at issue is below the threshold of 144.000,00EUR in Article 4(b) of the Directive. However, when transposing the Directive, the Slovenian legislator decided to enlarge the application of the Directive to all public procurements regardless of that threshold, which justifies this preliminary reference.

Article 2(1)(5) of Directive 2014/24 defines public contracts as 'contracts for pecuniary interest concluded in writing between one or more economic operators and one or more contracting authorities'. The Court of Justice recalls its judgment in IBA Molecular Italy (judgment of 18 October 2018, C-606/17, EU:C:2018:843), where the expression 'contracts for pecuniary interest' designates the contract's synallagmatic nature as an essential element of the public contract (para 25). Also, the same judgment confirms that a consideration in exchange does not necessarily consist of the payment of a sum of money (para 26).

It follows that Article 2(1)(5) of the Directive does not constitute the legal basis for rejecting a tenderer's bid on the sole ground that the price proposed is 0,00EUR. The award of the contract at issue could be of economic value to the tenderer to open up access to a new market or receive a reference letter, as argued by Tax-Fin-Lex (para 30). Moreover, Article 69(1) of the Directive establishes a procedure for the circumstance where a contracting authority perceives a tender to be abnormally low. 'The contracting authority is to require the tenderer to provide an explanation for the price or costs proposed' (para 32) and, in accordance to Article 69(3), 'may reject such a tender only where the evidence supplied does not satisfactorily account for the low level of price or costs proposed' (para 33). The Court then concludes by reinforcing that contracting authorities must carry the assessment of the information provided by the tenderer in compliance with the principle of equal treatment and non-discrimination be- 
tween tenderers, as well as transparency and proportionality, according to Article 18(1) of the Directive.

\section{Private International Law}

\section{Rebutting the Presumption that the Centre of Main Interests is the Habitual Residence when the Sole Immovable Asset is in Another Member State: Judgment in Case C-253/19 Novo Banco}

MH and NI, two natural persons, have filed for their own insolvency proceedings in Portugal, where they own their sole immovable property and have conducted and concluded the contracts leading to their insolvency. The element motivating the doubt of the referring judge is that $\mathrm{MH}$ and $\mathrm{NI}$ are resident in the United Kingdom.

In this context, the referring judge seeks guidance on the interpretation of Article 3(1) of Regulation 2015/848, which replaced and repealed Regulation (EC) No 1346/2000 on insolvency proceedings. More precisely, in the case of natural persons not exercising an independent business or professional activity, Article 3 (1) of the Regulation establishes a rebuttable presumption that the centre of main interest is in the place of habitual residence. The referring judge wants essentially to know if, in a situation such as the one in the main proceedings, the presumption is rebutted or not.

The Court of Justice answers vaguely. The first step of the analysis leads to interpret 'centre of main interest' of persons not exercising an independent business or professional activity as referring to 'the place where they conduct the administration of their economic interests or the majority of their revenue is earned and spent, or the place where the greater part of their assets is located' (para 24). For these persons, the CJEU explains, 'there is a strong possibility that that place corresponds to the centre of their main economic interests' (para 25).

In this context, it is particularly relevant to observe that recital 30 of the Regulation states that 'it should be possible to rebut this presumption, for example where the major part of the debtor's assets is located outside the Member State of the debtor's habitual residence'. The example given in the recital fits clearly with the present case, to the effect that the recital suggests that the presumption is rebutted in the main proceedings. However, the CJEU follows the Advocate General in holding that this recital shall not be read as meaning that the presumption is necessarily rebutted when the major part of the debtor's assets is located outside the Member State of the debtor's habitual residence.

Instead, what is needed is 'an overall assessment of all the objective criteria' (para 28), which include, in addition to the location of the assets, where 'the ma- 
jority of their revenue is earned and spent' (para 30). The CJEU, in essence, opts for an abstract interpretation of the provision, providing little guidance on how to apply this multi-factor test in the main proceedings.

It should also be noted that recital 30 gives examples relating to two types of debtors, companies and individuals not exercising an independent business or professional activity. For current purposes, it is noteworthy to compare the content of the recital in relation to these two situations. When a company has its central administration in a Member State different from the one where it is registered, one can rebut the presumption that the main centre of interests is in the latter following 'a comprehensive assessment of all the relevant factors establishes, in a manner that is ascertainable by third parties'. However, in the case of individuals not exercising an independent business or professional activity, the recital states only that 'it should be possible to rebut this presumption, for example where the major part of the debtor's assets is located outside the Member State of the debtor's habitual residence'. In this second case, the need for a comprehensive assessment is not mentioned explicitly. Contrary to the finding of the CJEU in the present case, this semantic difference suggests that the presumption that the habitual residence is the centre of main interests is rebutted in a situation such as the one in the main proceedings.

In other words, the decision of the CJEU boils down to amending recital 30 to the effect that a comprehensive assessment of the circumstance is needed also when the major part of the assets of an individual not exercising an independent business or professional activity is located outside the Member State of the debtor's habitual residence. The lack of any elaboration on why recital 30 does not provide a straightforward answer to the question of the referring judge makes the reasoning of the CJEU opaque on a point that is at the core of the whole decision.

Note: The primary responsibility for General Consumer Law, Unfair Contract Terms, Passenger Rights, Services Law, and Private International Law lies with Fabrizio Esposito; for the areas of Information Duties, Discrimination Law, and Public Procurement Law with Lucila de Almeida. 